\title{
ForeCASting MARKEt SHARES FROM \\ MOdELS FOR SALES
}

\author{
Dennis Fok, Philip Hans Franses
}

\begin{tabular}{|l|l|}
\hline ERIM REPORT SERIES RESEARCH IN MANAGEMENT \\
\hline ERIM Report Series reference number & ERS-2000-03-MKT \\
\hline Publication status / version & draft / version February 2000 \\
\hline Number of pages & 16 \\
\hline Email address first author & Dfok@few.eur.nl \\
\hline Address & Erasmus Research Institute of Management (ERIM) \\
& Rotterdam School of Management / Faculteit Bedrijfskunde \\
& Erasmus Universiteit Rotterdam \\
& PoBox 1738 \\
& 3000 DR Rotterdam, The Netherlands \\
& Phone: \# 31-(0) 10-408 1182 \\
& Fax: \# 31-(0) 10-408 9020 \\
& Email: info@erim.eur.nl \\
& Internet: www.erim.eur.nl \\
\hline
\end{tabular}

Bibliographic data and classifications of all the ERIM reports are also available on the ERIM website: www.erim.eur.nl 


\title{
ERASMUS RESEARCH INSTITUTE OF MANAGEMENT
}

\author{
REPORT SERIES \\ RESEARCH IN MANAGEMENT
}

\begin{tabular}{|c|c|c|}
\hline \multicolumn{3}{|c|}{ BIBLIOGRAPHIC DATA AND CLASSIFICATIONS } \\
\hline Abstract & \multicolumn{2}{|c|}{$\begin{array}{l}\text { Dividing forecasts of brand sales by a forecast of category sales, when they are generated from } \\
\text { brand specific sales-response models, renders biased forecasts of the brands' market shares. } \\
\text { In this paper we therefore propose an easy-to-apply simulation-based method which results in } \\
\text { unbiased forecasts of the market shares. An illustration for five tuna fish brands emphasizes the } \\
\text { practical relevance of the advocated method. }\end{array}$} \\
\hline \multirow{2}{*}{$\begin{array}{l}\text { Library of Congress } \\
\text { Classification } \\
\text { (LCC) }\end{array}$} & $5001-6182$ & Business \\
\hline & $5410-5417.5$ & Marketing \\
\hline \multirow{4}{*}{$\begin{array}{l}\text { Journal of Economic } \\
\text { Literature } \\
\text { (JEL) }\end{array}$} & $\mathrm{M}$ & Business Administration and Business Economics \\
\hline & M 31 & Marketing \\
\hline & C 44 & Statistical Decision Theory \\
\hline & M 31 & Marketing \\
\hline \multirow{4}{*}{$\begin{array}{l}\text { European Business Schools } \\
\text { Library Group } \\
\text { (EBSLG) }\end{array}$} & $85 \mathrm{~A}$ & Business General \\
\hline & $280 \mathrm{G}$ & Managing the marketing function \\
\hline & $255 \mathrm{~A}$ & Decision theory (general) \\
\hline & $280 \mathrm{~K}$ & Marketing science (quantitative analysis) \\
\hline \multicolumn{3}{|c|}{ Gemeenschappelijke Onderwerpsontsluiting (GOO) } \\
\hline \multirow[t]{3}{*}{ Classification GOO } & 85.00 & Bedrijfskunde, Organisatiekunde: algemeen \\
\hline & 85.40 & Marketing \\
\hline & 85.03 & Methoden en technieken, operations research \\
\hline \multirow[t]{3}{*}{ Keywords GOO } & \multicolumn{2}{|c|}{ Bedrijfskunde / Bedrijfseconomie } \\
\hline & \multicolumn{2}{|c|}{ Marketing / Besliskunde } \\
\hline & \multicolumn{2}{|c|}{ Marktaandeel, Forecasting } \\
\hline Free keywords & \multicolumn{2}{|c|}{ Sales Models, Market Shares, Forecasting } \\
\hline Other information & & \\
\hline
\end{tabular}




\title{
Forecasting Market Shares from Models for Sales
}

\author{
Dennis Fok* \\ Erasmus Research Institute of Management \\ Erasmus University Rotterdam \\ Philip Hans Franses \\ Econometric Institute and \\ Department of Marketing and Organization \\ Erasmus University Rotterdam
}

\begin{abstract}
Dividing forecasts of brand sales by a forecast of category sales, when they are generated from brand specific sales-response models, renders biased forecasts of the brands' market shares. In this paper we therefore propose an easy-to-apply simulation-based method which results in unbiased forecasts of the market shares. An illustration for five tuna fish brands emphasizes the practical relevance of the advocated method.
\end{abstract}

Key words: Sales models, Market Shares, Forecasting

*Address for correspondence: D. Fok, Erasmus University Rotterdam, Faculty of Economics, H16-12, P.O. Box 1738, NL-3000 DR Rotterdam, The Netherlands, e-mail: dfok@few.eur.nl. A computer program, which was used for all calculations in this paper, can be obtained from the corresponding author. 


\section{Introduction}

The comparison of various market share models in Brodie and Kluyver (1987) aroused substantial interest in the academic community for the topic of forecasting marketing performance measures. The subsequent discussion in several International Journal of Forecasting papers (several of these appeared in special issues in 1987 and 1994) concerned issues as model specification, parameter estimation, and the selection of functional forms. Another issue dealt with the question if it is sensible anyway to consider models for market shares instead of for sales, see for example Wittink (1987). Indeed, with the advent of the SCAN*PRO model, put forward in Wittink et al. (1988), there are by now many marketing forecasters who use this model for forecasting sales.

Of course, a natural and practically relevant question concerns the interaction between models for sales and the potential need of forecasts of market shares. Interestingly, an extensive literature search (covering articles in various marketing and forecasting journals) does not reveal any discussion of this matter. This may suggest that the question is not of interest. On the other hand, it may suggest that managers simply divide forecasts of brand sales by forecasts of category sales and take this as a forecast of market shares. Unfortunately, this approach is rather problematic, as the elements of this ratio are obviously not independent because the category sales include the brand sales. More precise, the thus generated forecasts of market shares are biased. Closer inspection of this problem reveals that analytical solutions are quite difficult, and hence one as to resort to simulation-based methods. In this paper we put forward such a method.

The outline of our paper is as follows. In Section 2, we discuss two methods for forecasting market shares given models for sales. The first method is the aforementioned division of forecasts (which we will call the naive method) and the second and more appropriate method relies on simulation techniques. In Section 3, we illustrate the practical relevance of the simulation-based method for an example concerning five brands. In Section 4, we conclude with some remarks. 


\section{Forecasting market shares}

Suppose that there are $I$ brands in a certain product category, and suppose the availability of weekly scanner data on sales and various explanatory variables. One possible form of a sales model assumes a multiplicative specification to relate explanatory variables such as promotion and prices to current sales, although other forms are of course also possible. The sales of brand $i, i=1, \ldots, I$ at time $t, t=1, \ldots, T$ can then be modeled as

$$
S_{i, t}=\exp \left(\mu_{i}+\varepsilon_{i, t}\right) \prod_{j=1}^{I} \prod_{k=1}^{K} \exp \left(x_{k, j, t}\right)^{\beta_{k, j, i}},
$$

where $\varepsilon_{t} \equiv\left(\varepsilon_{1, t}, \ldots, \varepsilon_{I, t}\right)^{\prime} \sim N(0, \Sigma)$ and where $x_{k, j, t}$ denotes the $k$-th explanatory variable (for example, price or advertising) for brand $j$ at time $t$ and $\beta_{k, j, i}$ is the corresponding coefficient for brand $i$. The normality assumption for the error terms is not strictly necessary, although with this assumption we have that least-squares estimates are the maximum likelihood estimates. The parameter $\mu_{i}$ is a brand-specific constant. The error process (or innovation process) $\varepsilon_{i, t}$ is usually assumed to be only correlated across brands and not over time, that is, $\varepsilon_{i, t}$ is assumed independent of $\varepsilon_{j, t-1}, j=1, \ldots, I$. Finally, by using the exponential transformation, one ensures that sales forecasts are always positive.

To capture lagged structures in (1), one can include lagged sales in the specification. The most general autoregressive structure follows from the inclusion of lagged sales of all brands. In that case, when a $P$-th order autoregressive structure is used, the model becomes

$$
S_{i, t}=\exp \left(\mu_{i}+\varepsilon_{i, t}\right) \prod_{j=1}^{I} \prod_{k=1}^{K} \exp \left(x_{k, j, t}\right)^{\beta_{k, j, i}} \prod_{j=1}^{I} \prod_{p=1}^{P} S_{j, t-p}^{\alpha_{p, j, i}} .
$$

Of course, this model can contain too many parameters, and one may wish to reduce that number by applying the usual variable selection techniques, once the parameters have been estimated. To estimate the parameters, the model usually is linearized by taking natural logarithms of the sales. The resulting equations form an $I$-dimensional vector autoregressive model with explanatory variables, to be abbreviated as $\operatorname{VARX}(P)$. The set of reduced-form equations becomes

$$
\log S_{i, t}=\mu_{i}+\sum_{j=1}^{I} \sum_{k=1}^{K} \beta_{k, j, i} x_{k, j, t}+\sum_{j=1}^{I} \sum_{p=1}^{P} \alpha_{p, j, i} \log S_{j, t-p}+\varepsilon_{i, t}
$$


with $i=1, \ldots, I$. As the error terms may be correlated across brands, the parameters in these reduced-form equations should be estimated using Generalized Least Squares [GLS].

Even though one constructs models for the sales of $I$ brands, it may be that forecasts of market shares are needed, also as these are sometimes easier to interpret than sales. For example, seasonal influences have less effect on market shares than on sales. The question we address in this paper is how one should generate such forecasts based on the models for brand specific sales.

\subsection{A naive method}

The market share of brand $i$ at time $t$, denoted by $M_{i, t}$, is defined as

$$
M_{i, t}=\frac{S_{i, t}}{\sum_{j=1}^{I} S_{j, t}} .
$$

Forecasts of the market shares at time $t+1$ based on information on all explanatory variables up to time $t+1$, denoted by $\mathcal{X}_{t+1}$, and information on realization of the sales up to period $t$, denoted by $\mathcal{S}_{t}$, should be equal to the expectation of the market shares given the total amount of information available, denoted by $\mathrm{E}\left[M_{i, t+1} \mid \mathcal{X}_{t+1}, \mathcal{S}_{t}\right]$, that is,

$$
\mathrm{E}\left[M_{i, t+1} \mid \mathcal{X}_{t+1}, \mathcal{S}_{t}\right]=\mathrm{E}\left[\frac{S_{i, t+1}}{\sum_{j=1}^{I} S_{j, t+1}} \mid \mathcal{X}_{t+1}, \mathcal{S}_{t}\right]
$$

It is important now to note that in general the right-hand side of $(5)$ is not equal to,

$$
\frac{\mathrm{E}\left[S_{i, t+1} \mid \mathcal{X}_{t+1}, \mathcal{S}_{t}\right]}{\sum_{j=1}^{I} \mathrm{E}\left[S_{j, t+1} \mid \mathcal{X}_{t+1}, \mathcal{S}_{t}\right]}
$$

This expression can be called a naive expectation. Hence, it is therefore not possible to obtain market shares forecasts directly from sales forecasts. A further complication is that is also not trivial to obtain a forecast of $S_{i, t+1}$, as the sales model is defined in logs, and as it is well known that $\exp (\mathrm{E}[\log X]) \neq \mathrm{E}[X]$. Therefore, forecasts of log sales cannot simply be transformed to sales forecasts using the exponential function. The forecast based on (6), where sales are forecasted by applying the exponential function to log sales forecasts, will be called a naive forecast.

For this naive method it is possible to obtain approximate (asymptotic) confidence 
intervals by using the, what is called, delta method. This method uses

$$
\begin{aligned}
\operatorname{Var}\left(\frac{S_{i, t+h}}{\sum_{j=1}^{I} S_{j, t+h}}\right) & =\operatorname{Var}\left(f_{i}\left(S_{1, t+h}, \ldots, S_{I, t+h}\right)\right) \\
& =\left(\frac{\partial f_{i}}{\partial \log S_{t+h}}\right)^{\prime} \operatorname{Var}\left(\log S_{1, t+h}, \ldots, \log S_{I, t+h}\right)\left(\frac{\partial f_{i}}{\partial \log S_{t+h}}\right),
\end{aligned}
$$

where $\operatorname{Var}\left(\log S_{1, t+h}, \ldots, \log S_{I, t+h}\right)$ can simply be obtained from (3). For $h=1$ this variance matrix is simply $\Sigma$. For $h>1$ the uncertainty in the lagged sales should also be included in the variance matrix for $\log S_{t+h}$, see for example Lütkepohl (1993). A possible drawback of these confidence intervals is that they are always symmetric, and more importantly, that the intervals are not necessarily confined to the $[0,1]$ interval.

\subsection{A simulation-based method}

Unbiased forecasts of the $I$ market shares should be based on the expected value of the market shares, that is,

$$
\begin{aligned}
\mathrm{E}\left[M_{i, t+1} \mid \mathcal{X}_{t+1}, \mathcal{S}_{t}\right] & = \\
& \int_{0}^{+\infty} \cdots \int_{0}^{+\infty} \frac{s_{i, t+1}}{\sum_{j=1}^{I} s_{j, t+1}} f\left(s_{1, t+1}, \ldots, s_{I, t+1} \mid \mathcal{X}_{t+1}, \mathcal{S}_{t}\right) d s_{1, t+1}, \ldots, d s_{I, t+1},
\end{aligned}
$$

where $f\left(s_{1, t+1}, \ldots, s_{I, t+1} \mid \mathcal{X}_{t+1}, \mathcal{S}_{t}\right)$ is the probability density function of the sales conditional on the available information, and $s_{i, t+1}$ denotes a realization of the stochastic $S_{i, t+1}$. By the model definition in (3) the distribution of $S_{t+1}$, given $\mathcal{X}_{t+1}$ and $\mathcal{S}_{t}$, is $\log$ normal, although of course other functional forms can be considered. Hence, in our case, $\left(\exp \left(S_{1, t+1}\right), \ldots, \exp \left(S_{1, t+I}\right)\right)^{\prime} \sim N\left(Z_{t+1}, \Sigma\right)$, where $Z_{t}=\left(Z_{1, t}, \ldots, Z_{I, t}\right)$ is the deterministic part of the model, that is,

$$
Z_{i, t}=\mu_{i}+\sum_{j=1}^{I} \sum_{k=1}^{K} \beta_{k, j, i} x_{k, j, t}+\sum_{j=1}^{I} \sum_{p=1}^{P} \alpha_{p, j, i} \log S_{j, t-p}
$$

The $I$-dimensional integral in (8) is difficult to evaluate analytically. We therefore choose to compute the expectations using simulation techniques. In short, using the estimated probability distribution of the sales we generate synthetic (artificial) realizations of the sales. Based on each set of these realizations of all brands, the market shares can be calculated. The average over a (preferably large) number of replications gives the expected value in (8). 
To be more precise, for one-step ahead forecasting, the sales can be simulated using

$$
\begin{aligned}
\varepsilon_{t+1}^{(l)} & =\left(\varepsilon_{1, t+1}^{(l)}, \ldots, \varepsilon_{I, t+1}^{(l)}\right)^{\prime} \text { from } N(0, \hat{\Sigma}) \\
S_{i, t+1}^{(l)} & =\exp \left(\hat{\mu}_{i}+\varepsilon_{i, t+1}^{(l)}\right) \prod_{j=1}^{I} \prod_{k=1}^{K} \exp \left(x_{k, j, t+1}\right)^{\hat{\beta}_{k, j, i}} \prod_{j=1}^{I} \prod_{p=1}^{P} S_{j, t+1-p}^{\hat{\alpha}_{p, j, i}},
\end{aligned}
$$

where the index $l$ denotes the simulation iteration. For every draw of $\varepsilon_{t+1}^{(l)}$, we calculate the corresponding realization of the sales, $S_{i, t+1}^{(l)}$, using the above equation. With a simulated realization of the sales, we can calculate the corresponding realization of the market shares using

$$
M_{i, t+1}^{(l)}=\frac{S_{i, t+1}^{(l)}}{\sum_{j=1}^{I} S_{j, t+1}^{(l)}} .
$$

Every vector $\left(M_{1, t+1}^{(l)}, \ldots, M_{I, t+1}^{(l)}\right)^{\prime}$ that is generated using this simulation method amounts to a draw from the joint distribution of the market shares. The expected market shares can therefore be estimated by averaging over all simulated market shares, that is,

$$
\mathrm{E}\left[M_{i, t+1} \mid \mathcal{X}_{t+1}, \mathcal{S}_{t}\right]=\frac{1}{L} \sum_{l=1}^{L} M_{i, t+1}^{(l)},
$$

Forecasting $h>1$ steps ahead is slightly more difficult as the values of the lagged sales are no longer known. Hence, for these lagged sales we should use the appropriate simulated values. For example, 2-step ahead forecasts can be calculated by averaging over simulated values $M_{i, t+2}^{(l)}$, based on drawings $\eta_{t+2}^{(l)}$ from $N(0, \hat{\Sigma})$ and on drawings $S_{i, t+1}^{(l)}$, which are already used for the 1-step ahead forecasts. Notice that the 2-step ahead forecasts do not need more simulations than the one-step ahead forecasts.

Finally, in case $h>P$, that is, all lagged market shares are unknown, the $h$-step forecasts are computed as $\mathrm{E}\left[M_{i, t+h} \mid \mathcal{X}_{t+h}, \mathcal{S}_{t}\right]=\frac{1}{L} \sum_{l=1}^{L} M_{i, t+h}^{(l)}$, where the relevant components are obtained from

$$
\begin{aligned}
M_{i, t+h}^{(l)} & =\frac{S_{i, t+h}^{(l)}}{\sum_{j=1}^{I} S_{j, t+h}^{(l)}} \\
S_{i, t+h}^{(l)} & =\exp \left(\hat{\mu}_{i}+\varepsilon_{i, t+h}^{(l)}\right) \prod_{j=1}^{I} \prod_{k=1}^{K} \exp \left(x_{k, j, t+h}\right)^{\hat{\beta}_{k, j, i}} \prod_{j=1}^{I} \prod_{p=1}^{P} S_{j, t+h-p}^{\left(l \hat{\alpha}_{p, j, i}\right.} \\
\varepsilon_{t+h}^{(l)} & =\left(\varepsilon_{1, t+h}^{(l)}, \ldots, \varepsilon_{I, t+h}^{(l)}\right)^{\prime} \text { from } N(0, \hat{\Sigma})
\end{aligned}
$$


When $h \leq P$, some of the lagged sales are observed, and in that case one can use the observed values instead of the simulated values.

An important by-product of our simulation-based method is that it is now also easy to calculate confidence bounds for the forecasted market shares. Actually, the entire distribution of the market shares can be estimated based on the simulated values. For example, the lower bound of a $75 \%$ confidence interval is that value for which it holds that $12.5 \%$ of the simulated market shares are smaller. In general, although of course the lower bound and the upper bound lie within the $[0,1]$ interval.

\section{Illustration}

The two forecasting methods discussed in the previous sections will be illustrated using a multiple-equation model for the sales of 5 brands of tuna fish. The data are analyzed in Hill and Cartwright (1994) for different reasons, and the relevant observations can be downloaded from the Journal of Business and Economic Statistics data archives. The data involve 52 weekly observations on 5 canned tuna fish brands, concerning sales and actually paid prices, amongst other variables. As our interest does not necessarily lie in the most adequate model for these variables, we confine our analysis to correlating sales with prices.

To keep the model relatively simple, we choose the own price, own price lagged and one-period lagged sales as the explanatory variables. Hence, in the model specification in (1) we have that $I=5, K=2, P=1$ and $\beta_{k, j, i}=0$ when $i \neq j$, and therefore in what follows we will ignore the subscript $j$ in $\beta_{k, j, i}$. In sum, our $\operatorname{VARX}(1)$ model for brand $i$ is

$$
\begin{gathered}
S_{i, t}=\exp \left(\mu_{i}+\varepsilon_{i, t}\right) \exp \left(P_{i, t}\right)^{\beta_{1, i}} \exp \left(P_{i, t-1}\right)^{\beta_{2, i}} S_{i, t-1}^{\alpha_{i}} \\
\left(\varepsilon_{1, t}, \ldots, \varepsilon_{I, t}\right)^{\prime} \sim N(0, \Sigma)
\end{gathered}
$$

Diagnostic checks on the model specification concerning residual autocorrelation and the approximate normality of the errors do not suggest serious misspecification.

The parameters in this model are estimated by GLS using the first 42 observations of the available data set. The last 10 observations are used to examine the out-of-sample forecasting accuracy. In Table 1 we report the estimated parameter values for this model. Most of the coefficients appear to be significant and have the expected sign. Notice that the expected value of $\beta_{2, i}$ is minus $\beta_{1, i}$, as in that case the price differences can be seen 
to have a negative effect. Only for brand 5, the current price coefficient is positive, but there it is seen to be insignificant.

As our empirical model contains current prices, we need to generate out-of-sample forecasts for the prices in order to generate out-of-sample sales forecasts. One option is to use random walk forecasts, that is, future prices are forecasted to be equal to the current prices. The information set $\mathcal{X}_{t+h}$ then only contains the prices up to period $t$. A second option, which we will also consider, is to use a simple vector autoregression [VAR] model to forecast prices.

We measure prediction accuracy by the root mean squared error [RMSE]. To be more precise, for $h$ steps ahead forecasts for the periods $t+1$ to $T$ for brand $i$, the relevant RMSE is calculated as

$$
R M S E=\frac{\sqrt{\sum_{l=t+1}^{T}\left(M_{i, l}-\widehat{M}_{i, l}\right)^{2}}}{T-t},
$$

where $\widehat{M}_{i, l}$ denotes the forecast of the market share of brand $i$ in period $l$ based on information up to period $l-h$.

In Table 2 we give the RMSE's (and the sum over the five brands), when we use random walk forecasts for the prices. We consider 1 week to 5 weeks ahead forecasting for all brands using both the naive method and the simulation method. The forecasts are made for period 43 up to period 52. The simulation forecasts are based on 10,000 replications. Clearly, for all forecast horizons and all brands the simulation method performs slightly better. Interestingly, the differences in forecasting accuracy between the naive and the simulation-based method seem to increase with an increasing forecast horizon. This may be due to the fact that the simulation method uses the entire distribution of unknown lagged sales, whereas the naive method only uses the forecasted value.

As discussed in Section 2.2, confidence bounds can also be calculated for the simulation method. In fact, the entire distribution can be computed. In Figure 1 we present the 1step ahead forecasts, the $75 \%$ confidence bounds and the realizations. It can be seen that not all realizations are within the confidence regions. This may suggest that the model is not adequately specified. Another possibility is that the regions are too small because no uncertainty about the forecasted prices is included. When a more elaborate model is used, like for example a (vector) autoregressive model for the prices, the uncertainty in price forecasts can also be included into the forecasting method. 
In Table 3 we present the estimated parameters in a VAR(1) model for the prices. This model can now be used to forecast sales. There are two advantages of using this model. First, the forecasts will be more accurate as in general better price forecasts lead to better market share forecasts. And, as mentioned, a second advantage is that the uncertainty in the price forecasts can be included into the forecasts and confidence intervals for the market shares.

In Table 4 we present the RMSE's for both the naive and the simulation forecasts up to 5 steps ahead, where we use the VAR(1) model for the prices. It should be noted here that the naive forecasts are thus only based on the forecasted prices, whereas our simulationbased forecasts use the entire (estimated) distribution of the prices. Again it clear that the simulation method performs best. For all forecasting horizons the simulation method has the smallest Sum Root Mean Squared Error. Notice that the errors are smaller than those corresponding with random walk price forecasts. Hence, the VAR(1) model for prices indeed adds some information to the market share forecasts.

The simulation-based method facilitates the inclusion of uncertainty in the price forecasts when computing the confidence bounds of the market shares. In the specific example considered, it would not be difficult to also include uncertainty about prices in the confidence bounds for the naive method as the prices are included linearly in (3). The forecast error in $\log S_{i, t+h}$ is then a linear combination of the error in the log sales model and the error in the price model, which are both normally distributed. The combined forecast error is therefore also normally distributed and the delta method in (7) still applies. However, it would become more difficult when the price, or another explanatory variable, is included in (3) using a non-linear specification. The forecast error would then no longer be a combination of normally distributed errors. In short, when one wishes to consider more complicated functional forms linking sales with explanatory variables, the simulation-based method becomes even more relevant.

Figure 2 gives the confidence bounds for 1-step ahead forecasting calculated using the simulation method. It is clear that the confidence bounds are much wider than the bounds given in Figure 1, where the uncertainty in prices is not taken into account. Notice the asymmetry of the confidence bounds for brand 3, that is, the forecasted value does not lie in the middle of the upper and the lower bound. 


\section{Conclusion}

In this paper we proposed a simulation-based method to generate forecasts for market shares in case one considers econometric models to correlate sales with explanatory variables. The method has various advantages over a naive method. The first is that it yields unbiased forecasts. The second is that it allows the confidence region of the forecasts to be asymmetric. Finally, the method is particularly useful if forecasts of explanatory variables are to be included, as the method takes their full forecast distribution into account. Our illustration showed some improvement of the new method over a naive method.

\section{References}

Brodie, R. J. and C. A. D. Kluyver (1987), A Comparison of the Short Term Forecasting Accuracy of Econometric and Naive Extrapolation Models of Market Share, International Journal of Forecasting, 3, 423-437.

Hill, R. C. and P. Cartwright (1994), The Statistical Properties of the Equity Estimator, Journal of Business \& Economic Statistics, 12, 141-147.

Lütkepohl, H. (1993), Introduction to Multiple Time Series Analysis, 2nd edn., SpringerVerlag, Berlin.

Wittink, D. R. (1987), Causal Market Share Models in Marketing: Neither Forecasting Nor Understanding, International Journal of Forecasting, 3, 445-448.

Wittink, D. R., M. Addona, W. Hawkes, and J. Porter (1988), SCAN*PRO: The Estimation, Validation and Use of Promotional Effects Based on Scanner Data, working paper, AC Nielsen, Schaumburg, Illinois, USA. 
Table 1: Estimated parameter values in an empirical sales model for 5 canned tuna fish brands. Standard errors are given in parentheses. The estimates are based on the first 42 observations

\begin{tabular}{cccccc}
\hline & $S_{1, t}$ & $S_{2, t}$ & $S_{3, t}$ & $S_{4, t}$ & $S_{5, t}$ \\
\hline Intercept & 5.298 & 9.549 & 5.904 & 7.616 & 5.030 \\
& $(1.214)$ & $(1.805)$ & $(1.941)$ & $(1.484)$ & $(2.367)$ \\
$\exp \left(P_{t}\right)$ & -8.643 & -4.497 & -10.737 & -8.434 & 3.093 \\
& $(0.712)$ & $(0.444)$ & $(0.866)$ & $(0.809)$ & $(8.195)$ \\
$\exp \left(P_{t-1}\right)$ & 7.328 & 0.742 & 7.511 & 6.083 & 0.040 \\
$S_{t-1}$ & $(0.939)$ & $(0.797)$ & $(1.440)$ & $(1.073)$ & $(8.539)$ \\
0.496 & 0.264 & 0.572 & 0.290 & 0.134 \\
$(0.091)$ & $(0.138)$ & $(0.118)$ & $(0.107)$ & $(0.129)$ \\
\hline \multirow{5}{*}{$=\left(\begin{array}{cccccc}0.207 & -0.024 & -0.023 & 0.036 & 0.028 \\
-0.024 & 0.142 & -0.023 & 0.026 & 0.010 \\
-0.023 & -0.023 & 0.147 & 0.030 & -0.006 \\
0.036 & 0.026 & 0.030 & 0.090 & 0.005 \\
0.028 & 0.010 & -0.006 & 0.005 & 0.011\end{array}\right)$}
\end{tabular}


Table 2: (Sum) Root Mean Squared Error for different forecast horizons over 10 forecasts for the naive method and the simulation-based [SB] method

\begin{tabular}{lcc|cc|cc|cc|cc}
\hline & \multicolumn{2}{c|}{ 1-step } & \multicolumn{2}{c|}{ 2-step } & \multicolumn{2}{c|}{ 3-step } & \multicolumn{2}{c|}{ 4-step } & \multicolumn{2}{c}{5 -step } \\
& Naive & SB & Naive & SB & Naive & SB & Naive & SB & Naive & SB \\
\hline Brand 1 & 17.55 & 17.38 & 20.45 & 20.07 & 18.53 & 18.12 & 15.51 & 15.24 & 15.91 & 15.81 \\
Brand 2 & 18.05 & 17.65 & 22.15 & 21.22 & 17.21 & 16.15 & 15.29 & 14.16 & 21.06 & 19.66 \\
Brand 3 & 26.37 & 26.14 & 30.09 & 29.52 & 24.01 & 23.24 & 21.32 & 20.64 & 25.07 & 24.80 \\
Brand 4 & 9.58 & 9.53 & 11.98 & 11.66 & 12.40 & 11.97 & 11.60 & 11.18 & 9.88 & 9.66 \\
Brand 5 & 4.77 & 4.75 & 6.83 & 6.67 & 7.57 & 7.29 & 7.02 & 6.66 & 5.61 & 5.33 \\
\hline Sum & 76.33 & 75.45 & 91.51 & 89.14 & 79.72 & 76.79 & 70.74 & 67.89 & 77.54 & 75.26 \\
\hline
\end{tabular}


Table 3: Estimated parameter values of a five-variate $\operatorname{VAR}(1)$ model for prices

\begin{tabular}{ccccccc}
\hline & Intercept & $P_{1, t-1}$ & $P_{2, t-1}$ & $P_{3, t-1}$ & $P_{4, t-1}$ & $P_{5, t-1}$ \\
\hline$P_{1, t}$ & 0.046 & 0.484 & 0.180 & 0.360 & -0.344 & 0.257 \\
& $(1.684)$ & $(0.126)$ & $(0.104)$ & $(0.167)$ & $(0.213)$ & $(2.814)$ \\
$P_{2, t}$ & -1.237 & 0.125 & 0.212 & 0.426 & 0.036 & 2.394 \\
& $(2.639)$ & $(0.198)$ & $(0.162)$ & $(0.262)$ & $(0.333)$ & $(4.409)$ \\
$P_{3, t}$ & -0.511 & 0.018 & -0.020 & 0.408 & 0.253 & 1.386 \\
& $(1.511)$ & $(0.113)$ & $(0.093)$ & $(0.150)$ & $(0.191)$ & $(2.525)$ \\
$P_{4, t}$ & 2.318 & 0.186 & 0.039 & -0.107 & 0.376 & -3.386 \\
& $(1.127)$ & $(0.084)$ & $(0.069)$ & $(0.112)$ & $(0.142)$ & $(1.883)$ \\
$P_{5, t}$ & 0.022 & -0.001 & 0.001 & -0.006 & 0.001 & 0.969 \\
& $(0.037)$ & $(0.003)$ & $(0.002)$ & $(0.004)$ & $(0.005)$ & $(0.061)$ \\
\hline
\end{tabular}


Table 4: (Sum) Root Mean Squared Error for different forecast horizons over 10 forecasts, while incorporating the forecasts obtained from a $\operatorname{VAR}(1)$ model for prices

\begin{tabular}{lcc|cc|cc|cc|cc}
\hline & \multicolumn{2}{c|}{ 1-step } & \multicolumn{2}{c|}{ 2-step } & \multicolumn{2}{c|}{ 3-step } & \multicolumn{2}{c|}{ 4-step } & \multicolumn{2}{c}{5 -step } \\
& Naive & SB & Naive & SB & Naive & SB & Naive & SB & Naive & SB \\
\hline Brand 1 & 19.00 & 18.95 & 17.66 & 17.87 & 16.10 & 16.61 & 15.25 & 15.66 & 14.48 & 14.96 \\
Brand 2 & 10.54 & 10.21 & 12.14 & 11.82 & 12.30 & 11.66 & 13.28 & 12.24 & 13.39 & 12.07 \\
Brand 3 & 22.46 & 22.04 & 22.67 & 21.82 & 23.15 & 22.15 & 22.40 & 21.33 & 21.99 & 20.89 \\
Brand 4 & 11.27 & 11.27 & 8.74 & 8.79 & 7.71 & 7.92 & 8.45 & 8.53 & 8.13 & 8.23 \\
Brand 5 & 4.39 & 4.59 & 5.12 & 5.43 & 4.80 & 5.19 & 4.64 & 5.02 & 4.63 & 4.99 \\
\hline Sum & 67.65 & 67.06 & 66.34 & 65.73 & 64.07 & 63.54 & 64.02 & 62.78 & 62.63 & 61.13 \\
\hline
\end{tabular}



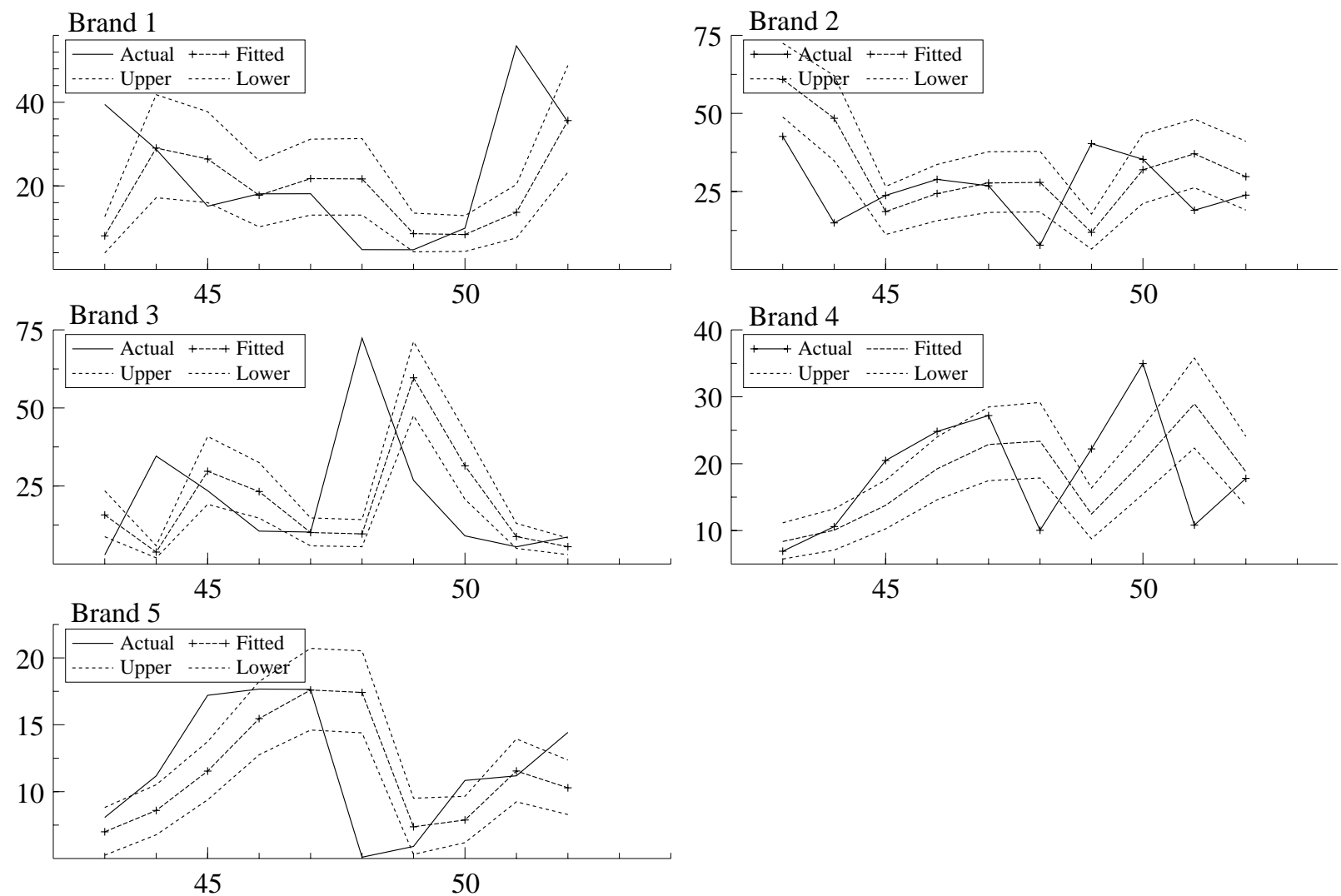

Figure 1: 1-step ahead forecasts with $75 \%$ confidence bounds, based on the simulation method. 

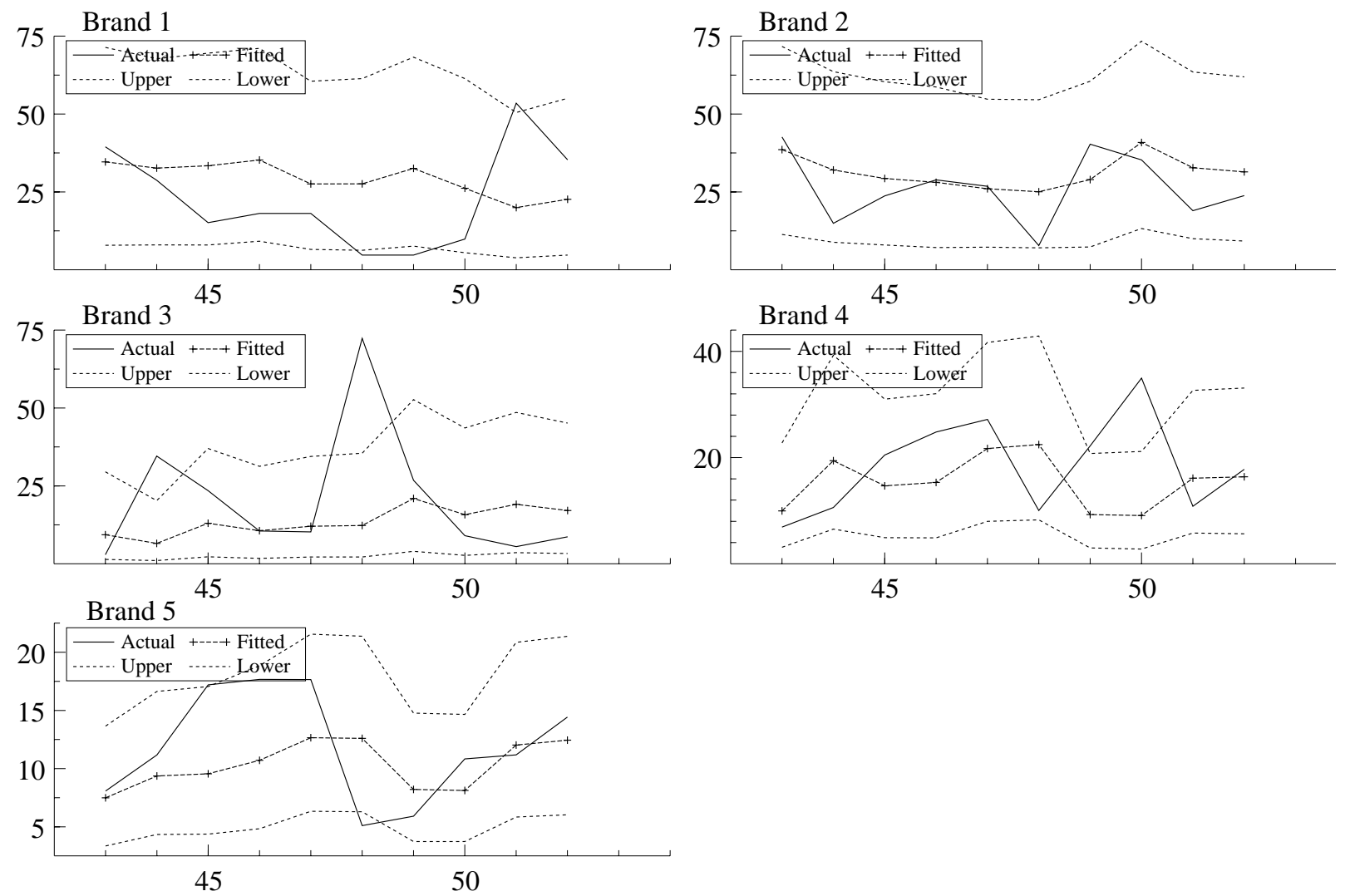

Figure 2: 1-step ahead forecasts with $75 \%$ confidence bounds, based on the simulation method using a VAR(1) model for prices. 


\title{
ERASMUS RESEARCH INSTITUTE OF MANAGEMENT
}

\author{
REPORT SERIES \\ RESEARCH IN MANAGEMENT
}

Other Publications in the Report Series Research* in Management

Impact of the Employee Communication and Perceived External Prestige on Organizational Identification, Ale Smidts, Cees B.M. van Riel \& Ad Th.H. Pruyn

ERS-2000-01-MKT

Critical Complexities, from marginal paradigms to learning networks, Slawomir Magala

ERS-2000-02-ORG

ERIM Research Programs:

LIS Business Processes, Logistics and Information Systems

ORG Managing Relationships for Performance

MKT Decision Making in Marketing Management

F\&A Financial Decision Making and Accounting

STR Strategic Renewal and the Dynamics of Firms, Networks and Industries 